\title{
Entrepreneurship
}

Jan a Jun $2020-$ v.4 - n.1

ISSN: 2595-4318

This article is also available online at: www.sustenere.co

\section{Um estudo bibliográfico sobre a contribuição do estágio para a formação de profissionais de administração}

A presente pesquisa aborda sobre a importância do estágio para os discentes e sua formação, apresentando a sua influência para a inserção dos mesmos no mercado de trabalho, e como essa vivencia pode proporcionar domínio teórico e prático, aonde irão se desenvolver profissionalmente e incrementar o aprendizado. O trabalho tem como objetivo geral, avaliar a importância do estágio para a formação do administrador, e como específico, mostrar a importância da atuação efetiva do estagiário nas organizações, verificar a contribuição das atividades de estágio para o desenvolvimento do discente (estagiário) e compreender a importância do estágio para a formação de competências, pela possibilidade de inserção do estagiário (discente) no mercado de trabalho, pelo contato com uma cultura organizacional. Relatar sobre as colaborações concedidas pela vivência do estágio e a integração entre a instituição de ensino e o mercado. Devido as mudanças externas se fazerem presente no dia a dia é necessário haver uma interação dos discentes com o meio profissional, para não haver nenhum tipo de impacto que poderá influenciar internamente. Para tal, desenvolveu-se um estudo exploratória, descritiva de abordagem qualitativa, utilizando a técnica de revisão bibliográfica em sites específicos como o Google, o Google Acadêmico, Scielo, dentre outros.

Palavras-chave: Mercado de Trabalho; Estágio; Competitividade; Administração; Formação.

\section{A bibliographic study on the contribution of the internship to the training of management professionals}

This research discusses the importance of the internship for students and their training, presenting their influence to the insertion of them in the labor market and how this experience can provide theoretical and practical domain, where they will develop professionally and increase learning. The work aims to evaluate the importance of the internship for the training of the administrator, and as a specific, to show the importance of the effective performance of the trainee in organizations, to verify the contribution of internship activities to the development of the student (trainee) and evaluate the importance of the internship for the training of skills, by the possibility of insertion of the trainee (student) in the labor market, by contact with an organizational culture. Report on the collaborations granted by the experience of the internship and the integration between the educational institution and the market. Due to the external changes being present in everyday life it is necessary to have an interaction of students with the professional environment, in order to do not have any kind of impact that may influence internally. For this, a qualitative study was developed, which for the performance of this study, a deepening on the subject was carried out through bibliographic consultations on specific sites for research such as Google, Google Scholar, Scielo, among Other.

Keywords: Labor Market; Internship; Competitiveness; Administration; Training.

Topic: Recursos Humanos

Reviewed anonymously in the process of blind peer.
Received: 20/01/2019

Approved: 18/04/2019
Lídia Sousa Pinheiro

Centro Universitário Vale do Salgado, Brasil

http://lattes.cnpq.br/0412958801458456

lidiasousinha@gmail.com

Maria Waldilene Sousa Teixeira

Centro Universitário Vale do Salgado, Brasil

http://lattes.cnpq.br/0494646222507948

lidiasousinha@gmail.com
Referencing this:

PINHEIRO L. S.; TEIXEIRA, M. W. S.. Um estudo bibliográfico sobre a contribuição do estágio para a formação de profissionais de administração. Entrepreneurship, v.4, n.1, p.24-33, 2020. DOI: http://doi.org/10.6008/CBPC2595-4318.2020.001.0004 


\section{INTRODUÇÃO}

O estágio é uma etapa importante, pois contribui na formação do discente e no seu processo de desenvolvimento, encurtando a distância entre o estudante e o mercado de trabalho. A formação de um profissional para o mercado de trabalho não pode ser marcada apenas pela teoria, é preciso que o discente conheça seu espaço de atuação e é o estágio que se encontra a oportunidade de o aluno expandir conhecimentos, associando a teoria à prática.

O cenário do mercado atual está se desenvolvendo cada vez mais, se tornando exigente com os profissionais. Com isso a cobrança com os mesmos se torna maior, tendo como consequência o aumento da competitividade, que para muitos acadêmicos se torna um problema, pois muitas instituições de ensino não preparam de forma adequada o aluno para o mercado, apresentando muitos conteúdos que não mostram a realidade profissional da sua futura profissão, trabalhando na área somente ao concluir o curso. Os discentes que obtiveram o estágio como experiência possui uma facilidade maior de ingressar no mercado de trabalho, sendo a maioria admitida pela própria empresa, que valoriza essa vivencia, pois percebem a importância da troca de informações entre os profissionais e estagiários, favorecendo a melhoria contínua e bons resultados, alavancando o desenvolvimento da empresa, pois o estágio garante ao discente uma oportunidade de se autodescobrir como profissional, de conviver com outros colegas de profissão, de vivenciar habilidades como responsabilidades que thes são conferidas e liderança de equipe, tão essenciais para a formação do futuro administrador. A pesquisa tem como pergunta de partida: qual a colaboração do estágio para o desenvolvimento das habilidades e competências inerentes ao administrador?.

A pesquisa tem como objetivo geral, avaliar a importância do estágio para a formação do administrador. E em termos específicos, mostrar a importância da atuação efetiva do estagiário nas organizações; verificar a contribuição das atividades de estágio para o desenvolvimento do discente (estagiário); compreender a importância do estágio para a formação de competências, pela possibilidade de inserção do estagiário (discente) no mercado de trabalho, pelo contato com uma cultura organizacional.

Justifica-se a iniciativa deste trabalho pela investigação de compreender a importância do estágio para a formação de competências, ressaltando a importância da contribuição do mesmo para a evolução dos conhecimentos do estagiário, oportunizando aos discentes sua inserção no mercado de trabalho. Contribuindo no âmbito social e educacional, agregando valores positivos para empresa, com suas ideias inovadoras e serviços de qualidade.

Vale ressaltar que para se obter uma formação com excelência a teoria é necessária, visto que o conhecimento é de suma importância para se tonar um bom profissional, mas é preciso muito mais que isso. Ao chegar no mercado é cobrado estágio como experiência, pois eles acham que essa vivencia entre o acadêmico e o mercado é necessária para completar o círculo curricular. Além do mais, mostra a competência do aluno, e suas desenvolturas, que podem contribuir bastante no desenvolvimento da empresa, exibindo estarem preparados para os grandes desafios que serão lançados pela organização que supostamente irá lhe contratar. 


\section{METODOLOGIA}

Trata-se de uma pesquisa exploratória, descritiva de abordagem qualitativa, utilizando a técnica de revisão bibliográfica. A pesquisa exploratória tem critérios, métodos e técnicas para a elaboração de uma pesquisa e visa oferecer informações sobre o objeto desta e orientar a formulação de hipóteses (CERVO et al., 2006).

O uso da pesquisa descritiva incide exatamente em descrever especificidades quanto a população, fenômeno ou das relações entre as variáveis a fim de obter resultados através das técnicas utilizadas frente a coleta de dados. Enfim, o uso da pesquisa descritiva é intrínseco as exploratórias, pois os pesquisadores que optam por utilizá-la são mais os da área social para ter uma análise da atuação prática (GIL, 2014).

Conforme Gonçalves (2003), “a pesquisa exploratória é aquela que se caracteriza pelo desenvolvimento e esclarecimento de ideias com o objetivo de oferecer uma visão panorâmica, uma primeira observação a um determinado fenômeno que é um pouco explorado". Tal afirmação significa dizer que a pesquisa explorativa é a procura de informações sobre algo que não se tem entendimento claro, para buscar ter uma compreensão melhor dos fatos. Segundo Gil (2014), "a pesquisa bibliográfica é desenvolvida a partir de material já elaborado, constituído principalmente de livros e artigos científicos", portanto para complementar o estudo, utilizou-se de pesquisa bibliográfica, que teve um importante auxilio com acervos de informações já organizadas.

Quanto à abordagem é qualitativa. A pesquisa qualitativa desenvolve a análise de conteúdo de um determinado assunto, pois é aplicada ao estudo da história das relações, das representações das crenças, das percepções e das opiniões, produtos dos entendimentos que os homens fazem a respeito de como vivem, como devem construir seus produtos de forma mecânica e a si mesmos, enfim, como sentem e pensam inseridos em um contexto social (MINAYO, 1992).

O método utilizado será o crítico dialético que segundo Gil (2014), o método dialético é fornecido por bases da interpretação dinâmica e da totalidade da realidade, estabelecendo os fatores sociais que não são entendidos quando são tratados de forma isolada, seja problemas econômicos, políticos, culturais entre outros. Necessita-se de um olhar crítico diante daquilo que é observado levando em conta toda a sua conjuntura histórica, o que promove uma avaliação mais profunda do objeto a ser estudado. Essa pesquisa por ser do tipo revisão bibliográfica ocorre no ambiente virtual, a partir das plataformas Scielo, Revista de Administração, Google acadêmico, Biblioteca Virtual quanto a estagio e formação do profissional de administração inclusive com literatura disponível em livros e monografias.

Para a realização do estudo terá como sujeitos, vários autores, nos quais os assuntos se correlacionam, colaborando com a pesquisa. Quanto aos critérios de inclusão que são apenas artigos e livros disponíveis em português, que tratem do tema de forma clara e objetiva na construção do trabalho. No critério de exclusão, publicações literaturas que não tivesse correlação com o tema a ser pesquisado, ainda que fossem publicações científicas.

Para a coleta dos dados dar-se-á por meio da seleção de livros e artigos, onde serão utilizados vários 
que abordem bem o tema proposto, colocados em uma pasta, para serem analisados com calma e utilizados depois. Será manuseado livros do acervo da biblioteca, para uma melhor compreensão do tema abordado, será feita uma observação minuciosa dos artigos para que não haja dúvidas sobre cada dado coletado. De acordo com Gil (2014):

A observação constitui elemento fundamental para a pesquisa. Desde a formulação do problema, passando pela construção de hipóteses, coleta, análise e interpretação dos dados, a observação desempenha papel imprescindível no processo da pesquisa. É, todavia, na fase de coleta de dados que o seu papel se torna mais evidente.

A observação nos ajuda a evidenciar cada dado, para que o trabalho tenha um leque de informações que possam informar o leitor de forma clara.

\section{DISCUSSÃO TEÓRICA}

\section{O estágio supervisionado e a formação do profissional de Administração}

O estágio supervisionado é um período de preparação e aperfeiçoamento da profissão, ou seja, uma atividade de aprendizado social e cultural que será como um complemento do ensino, onde é construída uma identidade profissional, com objetivo de capacitar o discente para que o mesmo possa exercer com qualidade no mercado de trabalho (SILVA et al., 2018).

Nossas vidas são compostas por etapas, sendo cada uma delas importantes e necessárias para se obter o resultado desejado. Assim como todas as outras etapas acadêmicas, o estágio é uma que não se pode ficar de fora do âmbito de aprendizagem, pois, é no dia a dia que se pode obter uma visão clara do que realmente ocorre na realidade, com isso, se torna uma ferramenta indispensável para o futuro profissional e sua inclusão no mercado, tornando-se um diferencial em entrevistas, por ter vivenciado essa experiência (MARQUES, 2018).

No momento presente, o estágio é um ato bastante exibido, no mercado. Muitos discentes buscam por essa colocação para incrementar sua carreira, pois, logo após, adentrar na área acadêmica, a busca pelo estágio é constante, pois é uma forma de iniciar a trajetória profissional, não visando só à vivência, como também a experiência, podendo assim, descobrir-se como profissional e se preparar para as exigências das instituições hodiernas. Por ser visto como uma forma de expandir os conhecimentos, o estágio é bem aceito pelas instituições de ensino, tanto que o outorgam em algumas disciplinas, como indispensáveis para a grade curricular.

Perante as necessidades referentes ao ensino e formação do administrador, a vivencia do estágio é uma forma de complementar o aprendizado durante o curso e colaborar com a evolução profissional do discente. O conhecimento é algo que ao decorrer do tempo vai ser lapidado pelo aluno, de acordo com as disciplinas abordadas, projetos executados, palestras, eventos, entre outros, tudo isso serve como auxilio e aprofundamento no conhecimento e evolução na sua área, além de proporcionar uma vantagem competitiva no mercado de trabalho.

É relevante ressaltar que, quando bem desenvolvido e supervisionado, essa vivência com o mercado aprimora e estimula a transformação entre a vida acadêmica à profissional, rompendo todo e qualquer tipo 
de incerteza e insegurança. Além disso, é um período de teste em algumas áreas especificas e algumas de maior interesse do discente, onde o mesmo poderá aproveitar a oportunidade para se decidir onde irá focar (PEREIRA, 2013).

O mercado de trabalho requer profissionais habilitados para atuar no meio multicultural. Dessa forma se torna necessário construir esse conhecimento em movimento constante entre reflexão e ação, para poder identificar onde se deve aprimorar na formação acadêmica, pois enquanto estagiários existe a probabilidade de não sabermos exatamente ao certo as habilidades que ainda não obtivemos e precisamos ter ao findar o curso, dispondo da oportunidade de questionar ao errar, para se ter uma preparação adequada, visto que, ao se formar o olhar do mercado de trabalho para o discente será de forma profissional, e a exigência será cobrada a altura (FERNANDES, 2007).

Atualmente para as Instituições de Educação Superior (IES), a competência, conhecimento e informação, possui um papel de múltipla importância, onde subsequentemente para os discentes, que futuramente serão profissionais e para as organizações que carece desses especialistas. Por isso, ao escolher uma IES, o universitário deseja por uma formação que envolva uma maior série de fatores, para que possa ter um ótimo nível de qualidade educacional. Sendo assim, as universidades proporcionam um conjunto de recursos para essa formação (GOMES et al., 2016).

Segundo Pereira (2013) é importante destacar que, o caminho da instituição para o meio profissional, é a porta de entrada para a vida adulta. Acham-se vários caminhos para adentrar no mercado, mas o estágio vem a ser o limite entre a universidade e o mundo produtivo, dado que na maioria das vezes é visto como uma possibilidade de ingressar e de obter uma afeição nas organizações. O discente ao vivenciarem e fazerem parte do meio profissional ensaia sua atuação futura, aplicando seus conhecimentos obtidos em sala de aula e desenvolvendo seus talentos, tendo contato direto com as dificuldades reais do mercado de trabalho. Obtendo uma visão e percepção diferente do meio profissional, onde despertará o desejo em eliminar tais falhas existentes.

Os desafios enfrentados durante o desenvolvimento profissional dos discentes são muitos e quando se refere ao estágio só aumenta, pois, trata-se de uma experiência com proporções formadoras e sociopolíticas, que devem ser construídas com o acompanhamento da instituição e sua estrutura e prática didática, para que haja uma educação capacitada ética e cooperativo a favor do desenvolvimento humano e melhoria da qualidade de vida (BEZERRA et al., 2017).

Além de o estágio proporcionar situações reais de uma empresa e ser importante para ter experiência a mais no currículo, auxilia o discente a identificar em qual área deseja se especializar, por meio da sua experiência preliminar, logo saberá onde foi seu desempenho mais significativo ou onde se identificou melhor. Tendo também como vantagem, o estagiário terá a oportunidade de identificar os problemas enfrentados diariamente na empresa, com isso, desenvolverá soluções para suprir a essas necessidades, gerando iniciativas que o ajuda na resolução de problemas enfrentados pelas organizações.

O estágio supervisionado é um método pedagógico, no qual a IES se torna responsável, por proporcionar ao universitário um ponto de vista da realidade. Que tende de oferecer ao futuro profissional 
a teoria e a prática, onde requer disposição e convívio com o meio que se estará atuando, aceitando as tarefas e se ligando ao novo mundo, incentivando na desenvoltura do acadêmico para encarar as constantes mudanças no mercado de trabalho e instituições, porém, constata-se que a formação do administrador deve estar voltada a versatilidade. É ideal que o discente se situe estrategicamente em função das insuficiências do mercado, compreendendo a sua importância no meio do âmbito social, e seu valor para a sociedade. No momento em que o mesmo consegue executar o que foi adquirido em sala de aula, ele estará demonstrando saber o conteúdo aplicado, e apresentando firmeza em sua competência como profissional.

É importante ressaltar que o professor-orientador, acompanhe de perto o procedimento de cada estagiário, pois alguns já possuem uma desenvoltura melhor, por terem vínculo com alguma empresa, serem proprietários ou sócios, mas há aqueles que nunca obtiveram experiência nenhuma e necessitam de uma atenção maior. Conforme o mercado de trabalho, por falta de vivências, preparação durante a formação acadêmica e familiaridade com sua profissão, os profissionais estão gradativamente menos habilitados para ingressarem no meio empresarial. Alguns formandos fazem noção do que realmente o curso representa, a partir do instante em que ingressa em um estágio (FARIA et al., 2012).

\section{Formação do administrador e as exigências do mercado de trabalho}

Nos últimos tempos, devido as constantes mudanças o mercado de trabalho busca por profissionais mais qualificados, devido a isso cabe aos formandos e discentes se precaverem para adentrar no meio profissional e encarar as inovações e exigências feitas pelas organizações. Algumas dessas mudanças interferem diretamente no apresto e desempenho do profissional. Com as propostas de emprego limitadas, é necessário se destacar e se tornar um diferencial, tanto para uma contratação, quanto para manter-se no comércio. Devido as empresas estarem adentradas em um âmbito de alta concorrência, é fundamental que as mesmas procurem por se adaptarem a essa situação, que pode ser feito através de buscas por especialistas capacitados e flexíveis (MURAD, 2017).

O administrador deve estar sempre se adequando as necessidades atuais, aprimorando-se dia após dia. É nítido que ao longo do processo de sua formação as melhorias e atualizações passam a ser ainda mais cobradas, para que possam ser resultantes no meio organizacional. O estágio contribui para haja uma execução de qualidade, pois além de desenvolver suas habilidades e conhecimentos, á uma possibilidade maior de ingressar no mercado, e pode-se notar que os indivíduos procuram por essa qualificação e adaptação às demandas, que é cada vez mais crescente. A procura por esses tipos de profissionais é uma forma de escape que as empresas encontram para se manterem vivas e competitivas no meio organizacional (MURAD, 2017).

Ser administrador vai muito além do que apenas gerencia ferramentas gerenciais. É necessário obter bastante conhecimento para lidar com as situações ofertadas pelo mercado de trabalho. $\mathrm{O}$ estágio é uma atuação referente a área de estudos do curso do discente que engloba a sua formação acadêmica, tendo como foco acarretar experiência, objetivando obter competências próprias da carreira. Sendo ele também, um meio de enturmar a prática social, organizações, discentes e instituições de ensino, atendendo a procura 
e necessidade por profissionais qualificados (PEREIRA, 2013).

A instituição onde o administrador terá sua formação, pode ter uma influência bastante significativa na concepção e visão do mesmo. Ainda que essa importância colabore para a formação, existem certos desequilíbrios no que desrespeita aos discentes de administração, que além de serem uma quantidade significativa de formandos, ainda disputam vagas de mercado com os demais cursos. Vale ressaltar que a fartura de vagas para gestores não se prolifera na mesma proporção que a profissionais administradores. Como consequência, muitos estão desempregados, ou em funções não pertencentes à sua formação, e até mesmo ganhando menos do que é merecido. Dessa forma é preciso se aprofundar e compreender sobre as dificuldades seguintes nas etapas de capacitação para o meio profissional (CALIARI et al., 2017).

A qualificação dos profissionais é muito importante para as instituições, pois resulta em rendimento para a mesma, proporcionando mais produtividade e eficiência, alcançando seus objetivos. Devido a muitas evoluções as empresas se tornaram bastantes rigorosas com seus funcionários, com isso, muitos formandos não exercem funções na área formada, pois o mercado procura por profissionais de alta competência. Desta forma, as exigências para a contratação se tornou ainda mais delicada, sendo assim, despertando o querer dos discentes em se desenvolver e atualizar ainda mais seus conhecimentos, para saber the dar com os obstáculos ao saírem da faculdade e encararem o mercado de trabalho, que visa analisar a probabilidade que o recém-formado tem de suprir as necessidades expostas pelas instituições, e poder identificar qual seu diferencial para que o mesmo se mantenha ou se torne empregado.

O diferencial em um profissional é muito relevante e pode ser bastante significativo, principalmente quando o gestor de uma empresa reconhece seu potencial e nota que necessita da sua participação na organização, para que possa colaborar no desenvolvimento e alavancar a empresa. Demonstrando essa valorização ao profissional a probabilidade de sucesso na empresa é significante, sendo assim toda a organização tirará bom proveito de um trabalho bem realizado. $\mathrm{O}$ que torna o administrador ser destaque como diferencial é a forma como o mesmo se desenvolve de acordo com seus conhecimentos e a forma de usá-los para contribuir na evolução da empresa, detectando seus principais concorrentes e logo obter estratégias para usar e ter sucesso, sendo assim, os bons resultados da sua gestão são perceptíveis.

Profissionais não qualificados podem conduzir empresas a falência por fazerem uma má gestão, isso é resultado da ausência de experiência e conhecimentos não adquiridos. É necessário haver acompanhamentos constantes, para prevenir que ocorram quedas e prejuízos. O estágio colabora bastante nos crescimentos destes profissionais, os preparando para esses tipos de situações, pois os conhecimentos que são absorvidos e vivenciados no dia a dia Ihe servirão futuramente para aplicar em sua função. Podendo até permanecer no local onde estagiou de acordo com seu desempenho e colaboração feita para o crescimento da organização. E para os que não obtiveram a oportunidade de estágio, tem uma vantagem menor (SILVA et al., 2013).

\section{Aprendizagens no contexto de trabalho e desenvolvimento de competências}

A aprendizagem organizacional estar relacionada ao modo como as instituições compõem, 
acrescentam e organizam informações e normas em volta de sua qualificação e em harmonia com a elaboração de culturas adaptativas que consintam a eficiência organizacional pelo meio da melhoria do uso do conhecimento e das competências de trabalho (BRITO, 2008).

Autoconhecimento e autodesenvolvimento são elementos que surgem através do aprendizado. Autoconhecimento é após instruir-se de algo novo mudar suas ações, e ter facilidade de detectar atividades que são ou não são do seu agrado executar, identificar ou corrigir características do seu perfil profissional. Já o autodesenvolvimento está relacionado à função técnica do trabalho e é vista com importância para o futuro profissional, devido o mesmo sentir-se capacitado para novas oportunidades de emprego dentro ou fora da empresa que pertence.

Algumas instituições concluíram que possuir o dom de aprender é o único caminho que nos leva até a renovação e crescimento. No pensamento institucional, o conhecimento é apontado como uma forma de poder concretizar os objetivos estratégicos. Para isso, é necessário que os líderes da instituição repassem como se pode alcançar a estratégia da corporação através da aprendizagem, e quais são as decisões e ações cotidianas que corroboram com isso. Interligar as ações e decisões do dia a dia aos fins estratégicos contribui para a percepção dos colaboradores enxergarem o valor e colaboração das tarefas desenvolvidas diariamente, e qual seu impacto no sistema organizacional. Por tanto, o conhecimento é significativo para a instituição, pois é a partir daí que ocorre a modificação entre a aplicação de ideias e a geração inovadora. Muitos acreditam que o conhecimento só é valido até o momento em que é utilizado para satisfazer suas necessidades atuais. Porém, as instituições que usam esse meio para seu desenvolvimento pessoal para a lucratividade, não solicitam aos indivíduos que reservem tempo para aprender. Nessas instituições o conhecimento estar interligado ao trabalho, não tendo como distinguir o próprio processo (BUKOWITZ et al., 2002).

O desempenho profissional eficaz é o que há aproximação de padrões ou que supre critérios de superioridade frequentemente e em longo prazo. São necessárias condições individuais e organizacionais para que haja um desempenho eficiente. É preciso saber executar e querer executar suas atividades diante de um padrão, e a instituição deve auxiliar, para que possam fazer, para se obtiver um trabalho eficaz. Porem existe também no ambiente de trabalho, dimensões de indisponibilidade, qualidade ruim, quantidade insuficiente de recursos, afetando o desempenho dos trabalhadores.

As organizações que se dispuseram a colaborar no aprendizado têm que amparar os indivíduos e equipes de colaboradores, para que os mesmos possam desenvolver seus conhecimentos e habilidades. Ou seja, instruí-los em áreas e técnicas que não são do seu conhecimento, oferecendo treinamentos, entre outros (MEISTER, 1999).

A aplicação do conceito de competência neste contexto, estar relacionada à forma de como a organização agrega valores organizacionais através dos serviços oferecidos pelos estagiários, aliando as práticas e conhecimentos obtidos pelos mesmos aos objetivos da organização, tendo como propósito absorver e pôr em práticas as inovações e propostas postas por eles. Findando a organização obtendo como lucro e vantagem competitiva (BITENCOURT, 2005). 
Ao executar as habilidades, atitudes e aprendizagens no mercado de trabalho, além de exibir que estes elementos complementam um ao outro e são interdependentes, cria um desempenho, que são repassados pela forma com que o indivíduo se comporta e se expressa na organização, tornando isso perceptível através de seus resultados e realizações (CARBONE, 2004).

\section{CONCLUSÕES}

O estágio pode ser visto como uma importante ferramenta para a formação do profissional de administração, uma vez que é nesse momento que o discente poderá utilizar os conhecimentos teóricos adquiridos no decorrer da graduação, buscando, através de uma autoanálise acerca das experiências pessoais e da própria atuação se autodescobrir como profissional. O objetivo deste estudo foi conhecer quais as contribuições que o estágio proporciona para o a formação de profissionais de administração (graduando). Os resultados obtidos possibilitaram algumas reflexões relacionadas ao estágio supervisionado, imprescindíveis no desenvolvimento da competência e da habilidade técnica dos discentes, futuros administradores.

O estudo teve como termos específicos, mostrar a importância da atuação efetiva do estagiário nas organizações; verificar a contribuição das atividades de estágio para o desenvolvimento do discente (estagiário); compreender a importância do estágio para a formação de competências, pela possibilidade de inserção do estagiário (discente) no mercado de trabalho, pelo contato com uma cultura organizacional. Onde o objetivo esperado através da construção deste artigo foi alcançado. Focando no objetivo geral do artigo que é avaliar a importância do Estágio para a formação do administrador, foi possível concluir que o estágio, em um aspecto geral, torna-se relevante para que o discente tenha mais facilidade de entrar no mercado de trabalho, pois assim eles poderão colocar em pratica tudo o que foi estudado em sala. Dessa maneira, estarão despertando a importância que o estágio proporciona para a construção da sua vida profissional.

\section{REFERÊNCIAS}

BEZERRA, D. S.; COSTA, E. N.; MASQUES, J. A.. Contribuições do estágio supervisionado na formação discente. Revista de Pesquisa Interdisciplinar, v.1, p.212-221, 2017. DOI: http://dx.doi.org/10.24219/rpi.v1iEsp.85

BITENCOURT, C. C.. Gestão de Competências e aprendizagem nas organizações. São Leopoldo: Unisinos, 2005.

BRITO, L. M. P.. Gestão de Competências, Gestão do Conhecimento e organizações de aprendizagem: instrumentos de apropriação pelo capital do saber do trabalhador. Pelotas: Cadernos de Educação, 2008.

BUKOWITZ, R. W.; WILLIAMS, R. L.. Manual de Gestão do Conhecimento. Porto Alegre: Bookman, 2002.

CALIARI, L.; MOREIRA, M. G.; BORGES, S. C.; CERQUEIRAADÃO, S. A. R.. A formação do administrador e a sua orientação profissional para o mercado de trabalho: a percepção dos acadêmicos de uma universidade privada do interior do Rio Grande do Sul. 2017.

CARBONE, P. P.; BRANDÃO, H. P.; LEITE, J. B. D.; VILHENA, R. M.. Gestão por competências e gestão do conhecimento. Rio de Janeiro: Campus, 2004.

CERVO, A.; BERVIAN, P. A.; SILVA, R.. Metodologia Científica. 6 ed. São Paulo: Pearson, 2006.

FARIA, E.; BRASIL, J.; MELO, J.; CABRAL, M.; RAMOS, P.; LIMA, P. I.. A formação profissional de estudantes de administração: a experiência do estágio supervisionado obrigatório. Anuário de Produções Acadêmico-Científicas dos Discentes da Faculdade Araguaia, v.1, n.1, 2012.

FERNANDES, M. L.. A importância do estágio para a formação do universitário. 2007.

GIL, A. C.. Como elaborar projeto de pesquisa. 5 Ed. São 
Paulo: Atlas, 2014.

GOMES, A. F.; TEIXEIRA, A. S. S.. Estagio supervisionado e aprendizagem: Contribuição do estágio do graduando de Administração para a formação profissional. Revista de Carreiras e Pessoas, v.6, n.3, 2016.

GONÇALVES, H. A.. Manual de Projetos de Pesquisa Cientifica. São Paulo: Avercamp, 2003.

MARQUES, V. R.; BARROS, M. N. R.; LUCENA, I. C. R.. Licenciados, formadores e professores dos anos iniciais: diálogos em práticas no estágio. Revista Communitas, v.2, n.3, p.23-40, 2018.

MEISTER, J. C.. Educação Corporativa: A Gestão do Capital Intelectual Através das Universidades Corporativas. São Paulo: Makron Books, 1999.
MINAYO, M. C. S.. O desafio do conhecimento: pesquisa qualitativa em saúde. São Paulo: HUCITEC; Rio de Janeiro: ABRASCO, 1992.

MURAD, I.. O mercado de trabalho na área de administração: analisando a formação profissional e as demandas das organizações. Revista Foco, v.10, n.2, p.8297, 2017.

SILVA, H.; GASPAR, M.. Estágio supervisionado: a relação teoria e prática reflexiva na formação de professores do curso de Licenciatura em Pedagogia. Revista Brasileira de Estudos Pedagógicos, v.99, n.251, 2018.

SILVA, W. R.; PEREIRA, B. G.. Letramento acadêmico no estágio supervisionado da licenciatura. Raído, v.7, n.13, p.37-60, 2013.

A CBPC - Companhia Brasileira de Produção Científica (CNPJ: 11.221.422/0001-03) detém os direitos materiais desta publicação. Os direitos referem-se à publicação do trabalho em qualquer parte do mundo, incluindo os direitos às renovações, expansões e disseminações da contribuição, bem como outros direitos subsidiários. Todos os trabalhos publicados eletronicamente poderão posteriormente ser publicados em coletâneas impressas sob coordenação da Sustenere Publishing, da Companhia Brasileira de Produção Científica e seus parceiros autorizados. Os (as) autores (as) preservam os direitos autorais, mas não têm permissão para a publicação da contribuição em outro meio, impresso ou digital, em português ou em tradução. 